\title{
Computer Modelling Average Annual Temperature in the Ground Layer of Air for the South of Western Siberia (Russia)
}

\author{
N. A. Shergunova, S. V. Solovev, K. S. Baikov, Yu. V. Chernenko, Ya. G. Poshivailo \\ Institute of Soil Science and Agrochemisry, Novosibirsk, Russia \\ Email: elka palkina@mail.ru, solovyev87@mail.ru, kbaikov@mail.ru, yuliachernenko89@yandex.ru, \\ yaroslava_po@mail.ru
}

Received November 2014

\begin{abstract}
Computer modelling the map of average annual temperature in the ground layer of air is performed for the southern part of Western Siberia (Russia). Four methods for data interpolation were used in ArcMap 9. Procedure of creation of digital model is described in detail. An original mathematic way for ranking of methods is proposed. According to results, Ordinary Kriging method gives the best approximation to the initial data.
\end{abstract}

Keywords

Computer Modelling, Temperature, Interpolation, Western Siberia

\section{Introduction}

In connection with development of computer technologies and wide introduction of computers in the sphere of scientific researches, the questions of their effective use for modelling, identication and scientific prognosis become more and more actual, for example, in ecology, climatology, soil science. The insufficient amount of models corresponding to the real data is observed in these sciences.

Difficulty of accumulation and processing of spatial data, as well as complication of simultaneous account of many factors influencing on a natural situation, do such procedure very difficult and expense. Researchers work in the conditions of permanent deficit of information: many attributes have a low level of informing, other parameters are absent often (Tsaregorodcev, \& Pogrebnaya, 1998).

The executed research has in focus development of effective paths for the study of spatial distribution of climatic indexes on the basis of the use of modern computer technologies. An aim of this research is mapping values of middle annual temperature on the basis of their spatial distribution and construction of the model of average annual temperature on long-term data for territory of the Novosibirsk Oblast (Western Siberia, Russia) using ArcGis.

The study area is located in the southeast West-Siberian plain and only in the utmost east go spurs SalairoKuznetsk mountain region, in its turn, determines its climatic features (Natural zoning and, 2010). The climate is 
continental with a long cold winter and hot short summer, average air temperature rises from north-east to south-west (Alisov, Berlin, \& Michael, 1954).

The important initial stage of work was executed is systematization and unitization of heterogeneous basic data as electronic databases and thematic layer in the geographic information system.

Creation of digital map of average annual temperature did a necessity the decision of next tasks:

1) input and systematization of the long-term measuring of temperature of air in the ground two-meter layer for 16 weather-stations on territory of the Novosibirsk area and thirty such items around (Climate handbook USSR, 1966; Scientific and applied climate handbook USSR, No. 17, 1998; Scientific and applied climate handbook USSR, No. 20, 1998);

2) filling of data base for values of average annual temperature, with attachment to position of weather-stations, including a height above a sea level (http://meteo.infospace.ru);

3) creation by means of the different algorithms realized in the environment of ArcGis, set of models of average annual temperature of the ground layer of air, for territory of south part of West Siberia (Novosibirsk Oblast and fragments of nearby regions);

4) discussion of results by means of criteria and expert estimation and choice most suitable from them.

\section{Materials and Methods}

Long-term (30 years) series of temperature data in the ground layer of air (using data from regional weatherstations, including 16 points in the Novosibirsk Oblast and 30 ones near her borders) were put into thematic database. Initial temperature diapason totaled $\left[-1.2^{\circ} \mathrm{C} ; 1.9^{\circ} \mathrm{C}\right]$.

In application of ArcMap 9.3, special layer with attributive table of information on names, measures of average air temperature, position of weather-stations above sea level, was generated on the first stage, using the coordinates of weather-stations.

Vertical gradient of temperature in troposphere, that equal .65 of a degree Celsius per 100 meters, was involved in modeling (Polikarpov, Tchebakova, \& Nazimova, 1986).

By the tools of ArcGis 9, data on average annual temperature in points were converted to temperature on 142 meters-medium altitude for registered weather-stations (ArcGis 9 ArcMap User guide, 2000-2004). Obtained temperature diapason totaled stations $\left[-1.49^{\circ} \mathrm{C} ; 1.95^{\circ} \mathrm{C}\right]$.

Thus, all indexes are put in one and the same plane, that allowed to choose a suitable method for data interpolation in ArcGis Spatial Analyst (ArcGis 9 Spatial Analyst User guide, 1999-2001).

As interpolation methods were used (Figure 1):
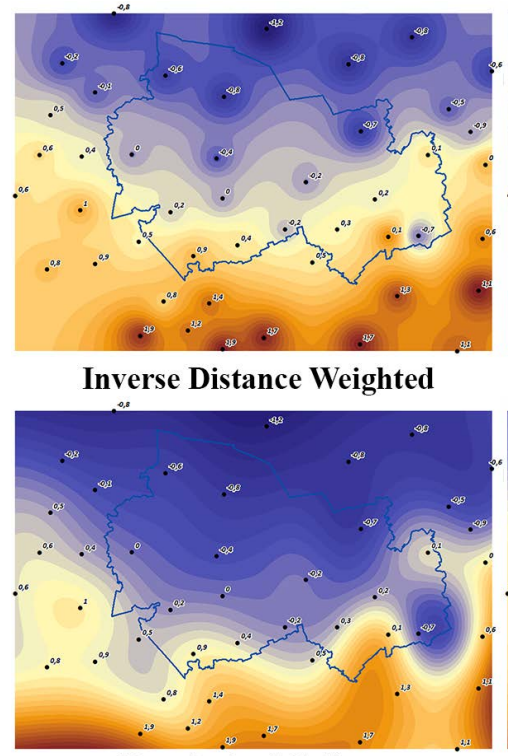

Regularized Spline

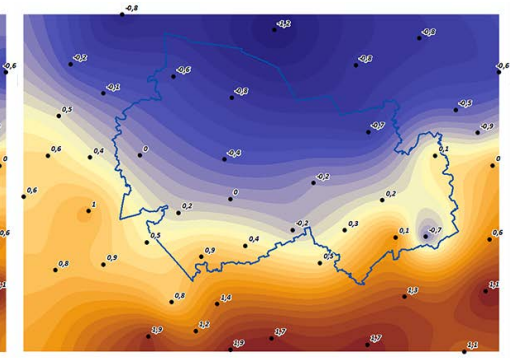

Ordinary Kriging (spherical)

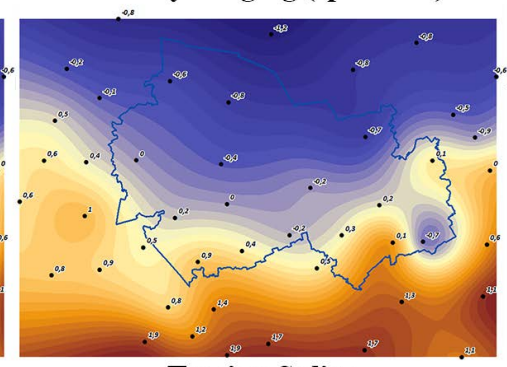

Tension Spline

Figure 1. Temperature rasters on the level 142 meters above sea level. 
- Inverse Distance Weighted

- Ordinary Kriging (spherical)

- Regularized Spline

- Tension Spline

Temperature levels (ranges) on resulting rasters have some differences for methods: Inverse Distance Weighted $\left[-1.489^{\circ} \mathrm{C} ; 1.949^{\circ} \mathrm{C}\right]$, Ordinary Kriging (spherical) $\left[-1.489^{\circ} \mathrm{C} ; 1.948^{\circ} \mathrm{C}\right]$, Regularized Spline $\left[-1.646^{\circ} \mathrm{C} ; 2.968^{\circ} \mathrm{C}\right]$, Tension Spline $\left[-1.569^{\circ} \mathrm{C} ; 2.123^{\circ} \mathrm{C}\right]$.

Then these rasters were performed by means of Spatial Analyst. Data in every cell were returned from virtual plane on their real height, using data for relief of SRTM (Shuttle Radar Topography Mission)

(http://gis-lab.info/qa/srtm.html), according to a formula:

$$
\text { [interpolation }]+\left(142-\left[S R T M \_1 k m . t i f\right]\right) \cdot 0.0065
$$

where interpolation-interpolated raster of average annual temperature, 142-medium altitude for registered weather-stations, SRTM.tif-raster for relief, .0065—vertical gradient of temperature, that equal .0065 of a degree Celsius per 1 meter.

Four digital average annual temperature models having $1 \mathrm{~km}$ pixel were generated in projection UTM WGS 84 (Universal Transverse Mercator (World Geodetic System 84)) for the southern part of Western Siberia in Russia (Figure 2).

Novel temperature levels (ranges) for digital maps are: Inverse Distance Weighted $\left[-1.975^{\circ} \mathrm{C} ; 2.065^{\circ} \mathrm{C}\right]$, Ordinary Kriging (spherical) $\left[-2.094^{\circ} \mathrm{C} ; 2.074^{\circ} \mathrm{C}\right]$, Regularized Spline $\left[-2.891^{\circ} \mathrm{C} ; 3.396^{\circ} \mathrm{C}\right]$, Tension Spline $\left[-2.443^{\circ} \mathrm{C} ; 2.503^{\circ} \mathrm{C}\right]$.

\section{Results and Discussion}

Cartographic model were further analyzed in a software product Global Mapper, ver. 16. As an indicator of selected zero isotherm (Figure 3). Zero isotherm on method Inverse Distance Weighted noticeably displaced in the area of positive temperatures relatively two of meteo stations with zero average annual temperature. In the model by Kriging zero isotherm very accurately approximated to zero points. Two models on Regularized Spline and Tension Spline similar by Kriging, but plus isotherm displaced toward the periphery in south-west and understated isotherms in foothills Salair (south-eastern part of the territory).

As a result, of the methods considered interpolation temperature data method Ordinary Kriging selected the best (Figure 4).
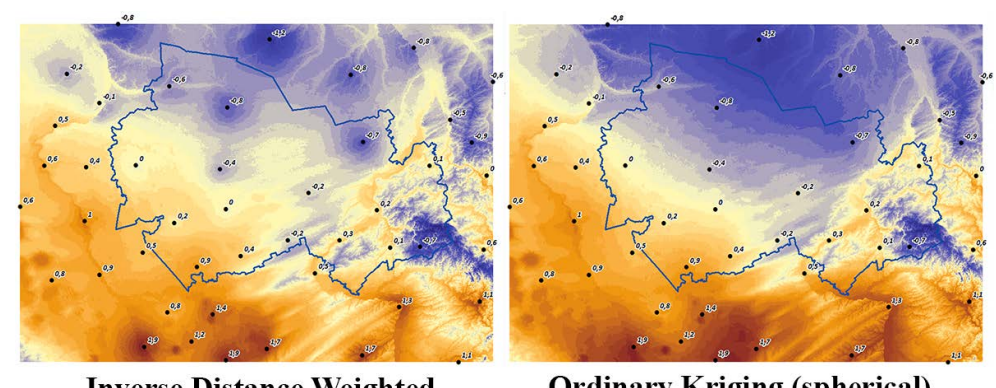

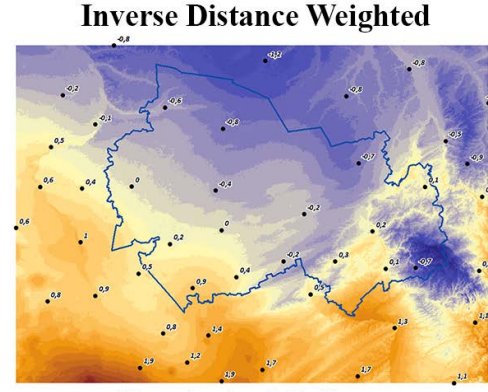

Regularized Spline

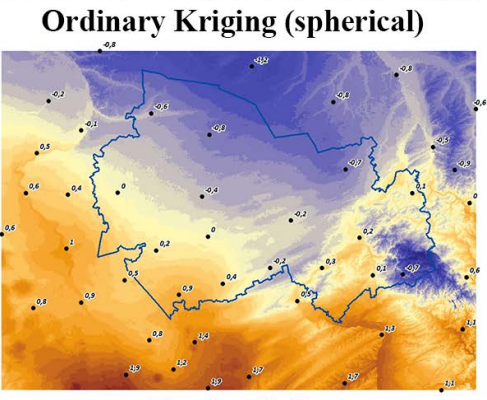

Tension Spline

Figure 2. Four digital average annual temperature models, calculated by different interpolation. 

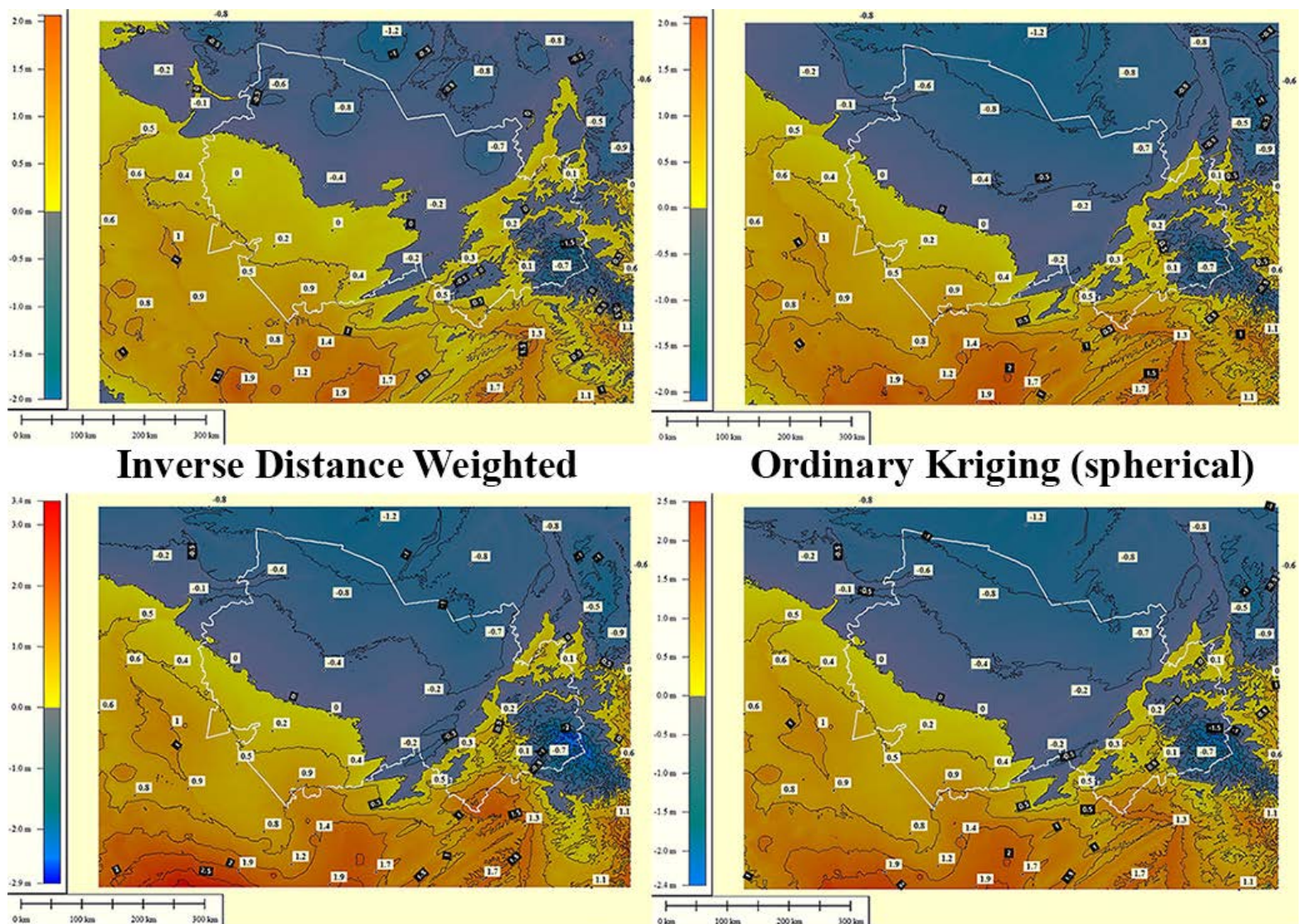

Regularized Spline

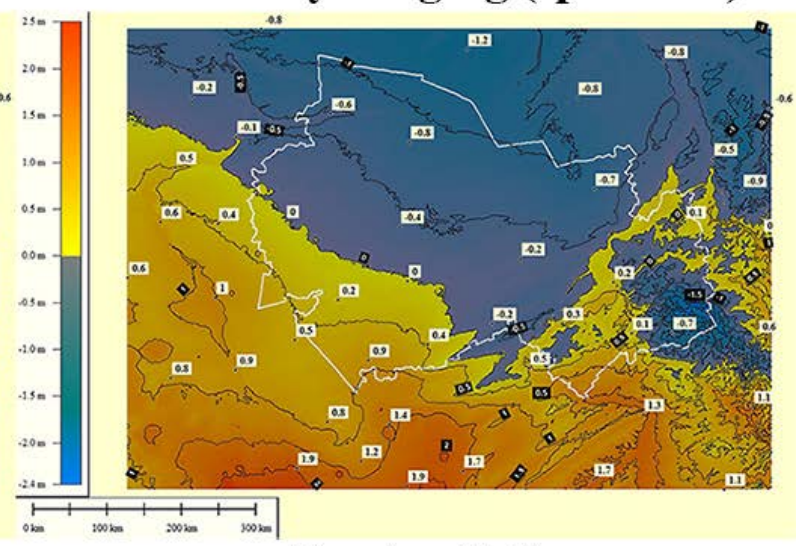

\section{Tension Spline}

Figure 3. Four digital average annual temperature models with isotherms through $.5^{\circ} \mathrm{C}$.

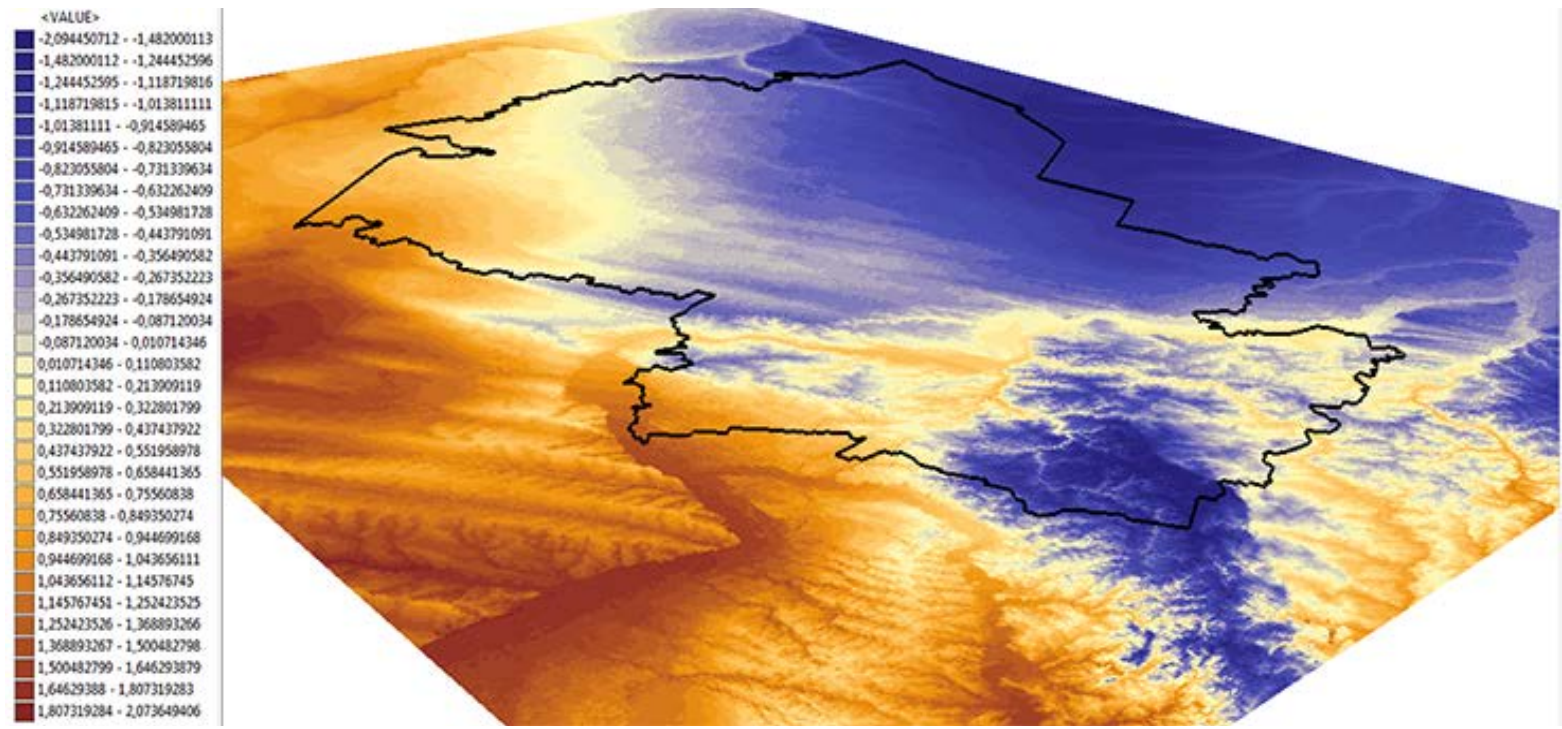

Figure 4. 3D-model for average annual temperature in southern part of Western Siberia (Russia). Ordinary Kriging.

This investigation is performed in Institute of Soil Science and Agrochemistry, Novosibirsk, Russia; under financial supporting of Russian government scientific program, project VI.54.1.3 (scientific leader Dr. K.S. Baikov). 


\section{References}

Climate Handbook USSR (1966). Vol. II. The Temperature of the Air and Soil. No. 18. Kazakh SSR. L., 656 p.

Scientific and Applied Climate Handbook USSR (1998). Ser. 3 Long-Term Data. Vol. 1-6, No.17. Tyumen and Omsk Region. SPb., 702 p.

Scientific and Applied Climate Handbook USSR (1998). Ser. 3 Long-Term Data. Vol. 1-6, No. 20. Tomsk, Novosibirsk, Kemerovo Region, Altay. SPb. 702 p.

http://meteo.infospace.ru

ArcGis 9 ArcMap User guide (2000-2004). ESRI. 219 p.

ArcGis 9 Spatial Analyst User Guide (1999-2001). ESRI. 219 p.

Polikarpov, N. P., Tchebakova, N. M., \& Nazimova, D. I. (1986). Climate and Mountain Forests of Southern Siberia. Novosibirsk, $226 \mathrm{p}$.

$\underline{\text { http://gis-lab.info/qa/srtm.html }}$

Tsaregorodcev, V. G., \& Pogrebnaya, N. A. (1998). Neural Network Method of Information Processing in the Prediction Problem Climatic Characteristics and Silvicultural Properties of Landscape Zones. Methods of Neuroinformatics. Collection of Scientific Works, Krasnoyarsk, 65-110.

Natural Zoning and the Current State of Soils of the Novosibirsk Region (Atlas) (2010). Novosibirsk, 20 p.

Alisov, B. P., Berlin, I. A., \& Michael, V. M. (1954). Course Climatology. Vol. 3. The Climate of the Globe. L., 321 p. 